\title{
The Effects of Different Types of Internal Controls on Self-Control
}

\author{
Drew Allen \\ Brigham Young University \\ William G. Heninger \\ Brigham Young University \\ Scott L. Summers \\ Brigham Young University \\ David A. Wood \\ Brigham Young University
}

\begin{abstract}
One reason companies implement internal controls is to reduce the likelihood of unethical behavior. Yet, ego depletion theory suggests that some controls may cause reductions in employees' self-control, which could undermine the ability of controls to reduce unethical behavior. We examine whether various types of controls impact self-control and ethical judgments. Our results show that contrary to the ego depletion hypothesis, we find no significant relation between self-control and internal controls. Furthermore, we find that controls have no effect on ethical judgments or ethical ideology. Thus, our results suggest that internal controls do not differentially impact self-control and ethical decision-making.
\end{abstract}

Keywords: Internal Controls, Ego Depletion, Ethics, Preventive Controls, Detec

\section{INTRODUCTION}

In order to ensure accurate financial reporting, deter fraud, and safeguard assets, companies implement internal controls throughout their organization (Committee of Sponsoring Organizations of the Treadway Commission [COSO] 1992, 2004, 2013). While internal controls serve an important role in reducing many types of risk, controls may also have unintended consequences that can negatively affect a company and its employees. For example, controls can undermine trust (Christ, Sedatole, Towry, and Thomas 2008), decrease employee work effort (Frey 1993), and reduce employee cooperation (Tenbrunsel and Messick 1999). The unintended psychological effects of a control will vary according to the attributes and execution of implemented controls; therefore, it is important that companies understand which attributes are associated with negative outcomes in order to effectively design and execute their internal control systems.

In this study, we test for an unintended effect of internal controls on a previously unresearched dimension: self-control. According to the theory of ego depletion from the psychology literature, tasks 
that require an individual to use self-control will diminish an individual's ability to exercise self-control in a later task (Baumeister, Bratslavsky, Muraven, and Tice 1998), which can result in unethical behavior (Mead, Baumeister, Gino, Schweitzer, and Ariely 2009), decreased problem-solving abilities (Baumeister et al. 1998), and a reduced ability to monitor one's own self (Vohs and Schmeichel 2003). If internal controls increase the amount of self-control resources needed to complete a task, these controls could leave individuals with less remaining willpower for other self-control tasks (such as other controlled tasks), potentially causing the aforementioned negative consequences.

To test this theory, we perform three $4 \times 1$ between-subject experiments with manipulations on the type of control placed on a data-entry task. After the initial data entry (or "ego depleting") task, each experiment includes a second task to measure loss in willpower (e.g., ego depletion) resulting from the initial task with various internal control manipulations. This allows us to test the effects that different kinds of controls have on an individual's self-control resources.

Our results suggest that internal controls of any type (e.g., preventive or detective controls) are not systematically related to reductions in self-control.We attain these null results in spite of several methodological strengths that include testing a total of 462 participants, using various measures of selfcontrol, using manipulations of internal control types that produced significant performance effects in prior studies (Christ et al. 2012; Christ et al. 2008), and varying the frequency of internal control coverage. Furthermore, and consistent with these results, we find that controls have no effect on a participant's ethical judgments or ethical ideology. These results are also consistent with a number of studies that have failed to replicate the ego depletion hypothesis (Haggar et al. 2016; Lurquin et al. 2016; Luquin and Miyake 2017, Job et al. 2010; Schmeichel and Vohs 2009; Ryan and Deci 2008) and present evidence that the hypothesis may not be as robust as previously thought. Thus, we conclude that the types of internal controls (preventive and detective have no discernable effect on self-control and ethical judgments as measured in our experiments).

These findings are important in that they suggest that the internal control classifications we examine do not reduce self-control or affect ethicality. Given the importance of internal controls in mitigating risk, these findings are important for managers, audit committees, and auditors in that they suggest that these types of controls do not create the unintended consequence of ego depletion. Thus, these groups can implement and evaluate different types of controls without having to worry about potential differential negative effects relating to self-control between the types of controls.

The rest of the paper proceeds as follows. In the next section we discuss prior literature and review our research question. We then discuss each of our experiments and the results. We conclude in the final section discussing limitations of our research and suggestions for future research.

\section{LITERATURE REVIEW AND HYPOTHESES}

Internal controls are widely considered to be an essential part of doing business (Geringer and Hebert 1989; Medcof 1997). Strong internal controls improve financial reporting quality (Doyle, Weili, and McVay 2007; Ashbaugh-Skaife, Collins, and Lafond 2009; Christ, Masli, Sharp, and Wood 2015), improve management guidance (Feng, Li, and McVay 2009), increase employee performance (Christ et al. 2012; Christ et al. 2016), reduce external audit delays (Ettredge, Chan, and Sun 2006), reduce external audit fees (Hogan and Wilkins 2008; Hoitash, Hoitash, and Bedard 2008), and may reduce cost of capital (Ogneva, Subramanyam, and Raghunandan 2007; Beneish, Billings, and Hodder 2008; Ashbaugh-Skaife et al. 2009). Thus, companies benefit from having strong internal controls.

Although companies may benefit from strong internal controls, it is important to remember that internal controls do have costs. In addition to the direct financial costs, prior research shows that controls can undermine trust (Christ et al. 2008) and result in reduced employee work effort (Frey 1993), motivation (Christ et al. 2012), and cooperation (Tenbrunsel and Messick 1999). Additionally, companies not only have to expend significant efforts to make sure controls are designed properly, but also have to assure that employees understand and follow control policies (Baxter, Holderness, and Wood 2016a, 2016b). 
While there are many different ways of classifying internal controls, one important distinction between types of controls is whether the controls are preventive or detective in nature (Christ et al. 2008; Christ et al. 2012; Christ et al. 2016). Preventive controls are defined as controls that "deter problems before they arise," while detective controls are meant to "discover problems that are not prevented" (Romney and Steinbart, 2015, p. 190). Even though both of these classifications of controls are meant to serve the same general purpose, these types of controls differ in the way that they address errors, and as such, may result in different costs with using each control.

Given the benefits and costs of internal controls, they are worthy of additional study. We assert that there may be another hidden cost of internal controls that has not been examined in prior research - that is, we assert that internal controls may impact employee self-control. To motivate this assertion, we turn to the theory of ego depletion.

Ego depletion theory states that self-control is a limited internal resource that can become depleted and eventually exhausted as self-control is exercised (Baumeister et al. 1998; Muraven, Tice, and Baumeister 1998). Like a muscle, self-control becomes increasingly fatigued as it is used, unless given a period of time to recover. While ego depletion argues that self-control can be "used-up," it has also been shown that things such as rest (Tyler and Burns 2008), food (Gailliot and Baumeister 2007), and positive affect (Tice, Baumesiter, Shmueli, and Muraven 2007) can replenish an individual's self-control stamina. Additionally, small acts of self-control over an extended period of time have been shown to increase overall self-control stamina (Muraven 2010). In one of the earliest tests of ego depletion theory, Muraven et al. (1998) showed that subjects who exercised self-control by repressing their emotions while watching a movie clip were not able to squeeze a hand grip for as long as those who did not have to repress their emotions before the hand grip task. In other words, "using up" self-control resources will result in fewer resources for subsequent self-control tasks.

The consequences of self-control depletion can be severe. For example, Gailliot et al. (2012) find that individuals who experience self-control depletion after completing an initial depleting task have fewer remaining self-control resources, and as a result, have a reduced ability to behave ethically on a subsequent self-control task. Additional research shows that relative to non-depleted individuals, depleted individuals are more likely to behave dishonestly (Mead et al. 2009), more likely to cheat (Barnes et al. 2011), and more likely to overstate their performance (Gino et al. 2011). Mead et al. (2009) show that depleted individuals are more likely to put themselves in morally compromising situations, and Gino et al. (2011) find that depleted individuals showed signs of reduced moral awareness and were less able to recognize that the cheating task presented to them was an ethical choice. Taken together, this research indicates that self-control depletion can have serious downstream consequences that can negatively affect individuals and businesses.

Several studies in the accounting literature have used ego depletion theory as a way to understand different accounting-related phenomenon. For example, Kremin (2014) found that after having auditors complete an ego-depleting task, they were less likely to correctly identify a misstatement in a subsequent analytical procedure task than were non-depleted participants. Additionally, Hurley (2015) proposes that several different components of an audit can result in depletion, including managing stress during busy season, having autonomy restricted through task assignment, and being required to complete complex tasks (e.g. fair value estimates, impairments, and valuation models). Majors, Shefchik, and Vitalis (2014) found that auditors with higher levels of trait skepticism were more prone to the effects of ego depletion than auditors with low trait skepticism, resulting in diminished performance in a subsequent accounting task. This result suggests that the mental exertion required to maintain professional skepticism can deplete an individual's self-control resources.

Seeing that depletion has proven to be relevant in accounting settings, we extend this research by examining if internal controls can increase the amount of self-control resources required to complete a given task. There are several studies in the depletion literature that provide evidence that internal controls could increase the self-control demands of a task. For example, Moller et al. (2006) finds that when autonomy is restricted, self-control tasks related to choice become more depleting. This suggests that an individual's reasons for regulating the self (autonomous vs. non-autonomous) play an important role in 
determining how depleting a task will be. To the extent that internal controls may restrict autonomy and force individuals to consume their self-control resources, we would expect these controls to induce additional self-control depletion. This is a plausible scenario, seeing as other research has deemed that certain control classifications (specifically preventive controls) restrict autonomy (Christ et al. 2012).

Another way that controls could be related to self-control depletion is through feedback. Muraven, Gagné, and Rosman (2008) find that when feedback related to performance is incorporated into a selfcontrol task, additional pressure is introduced to the task, and as a result, the task will be more depleting than the same task without any feedback. While both preventive and detective controls incorporate feedback, it is worth noting that feedback from preventive controls will always be immediate, but feedback from detective controls can be either immediate or delayed (Christ et al. 2012). Seeing as the timing of feedback is different for different classifications of controls, it seems possible that the amount of depletion from a control due to feedback could vary based on the timing of that feedback. Such an assumption is consistent with other research that has found the feedback timing of controls results in significantly different levels of performance on a task (Christ et al. 2012).

However, there are also compelling reasons to believe that internal controls will have no impact on self-control depletion. For example, the results of Moller et al. (2006) are based on an experiment that examines how restricting autonomy affects the self-control outcomes of a choice task, which is a different setting than restricting autonomy in a task that an individual has already agreed to take part in. This is a subtle, but possibly important distinction. Moller et al. (2006) also finds that when choice is removed, individuals perform at a higher level on subsequent self-control tasks than those whose autonomy is restricted on the initial task. This is likely due to the fact that making choices consumes self-control resources (Baumeister et al. 1998). Because an individual performing a controlled task has no choice but to interact with the control placed on the task, it is possible that controls may be seen as "choice eliminating" instead of autonomy-restrictive. This would mean that individuals performing a task with internal controls placed on it may actually conserve the self-control resources they would need to choose to perform the task correctly without any controls placed on it. There is also research that suggests that feedback has no effect on how depleting a task is (Wallace and Baumeister 2002), so differences in feedback timing between controls may make no difference in terms of self-control outcomes. For these reasons, it is possible that internal controls will not increase the self-control demands of a task.

Despite the mixed predictions from prior research, the effect of internal controls on self-control depletion remains an important empirical question with serious implications. If businesses and individuals wish to avoid the previously discussed negative ethical consequences that can result from depletion, it is important to understand how to conserve this valuable self-control resource. Therefore, we test whether preventive and detective internal controls affect self-control ability. Stated formally as a research question:

RQ1: Do either preventive or detective internal controls reduce self-control ability and thus ethical decision-making?

\section{EXPERIMENT 1}

\section{Participants}

Participants for all experiments were recruited from a pool of participants made up of various business school classes at a large private university in the western United States. The research also took place at the same university where the students were enrolled. All participants were recruited from various undergraduate and graduate university classes and received course credit for participating. Some participants received compensation, as described subsequently, all participants who applied to participate in the study were accepted into the study and there were no restrictions (other than students agreeing to be in the subject pool) for participating. The participant pool was selected to represent first year professional employees since they were within a few years of assuming this role; however, we acknowledge that for 
the most part, the participants were college students and not actual employees, which represents a limitation to our study.

\section{Procedure}

To test our hypotheses, we adhere to the two-task paradigm typically used in the ego depletion literature (Hagger et al. 2010). The two-task paradigm is designed such that the first task (the depleting task) is designed to induce depletion based on our experimental treatments and the second task (dependent task) measures depletion through performance on a subsequent self-control task.

\section{Depleting Task}

For our depleting task, we administered a typing task in which participants were required to type sentences of text as they appeared on a computer screen. Typing tasks have been used in other ego depletion studies (e.g., see Muraven et al. 2008 and Muraven, Shmueli, and Burkley 2006), but we note that the typing task used in this experiment differs from these other typing tasks in that our typing task is not meant to be depleting by itself. Rather, the typing task in our experiment provides an ideal setting in which we can cleanly implement our different control types in such a way that we can examine if introducing internal controls to the task creates self-control demands that otherwise would not have been present. Since our research question deals primarily with the differences between groups, it is not important if the task is depleting by itself or not, rather it is important whether the controls cause differences in depletion. We also note that while our typing task is not meant to simulate a real-world business task that employees would be asked to perform, the results of this experiment should allow us to make conclusions about the internal controls placed on the task, and that these conclusions about internal controls have implications for all tasks that leverage these kinds of controls in practice. We note that we use an abstract task rather than a real-world accounting task in order to have a valid test of the theoretical psychological mechanisms of internal controls rather than have mundane realism. That is, our experiment follows a long line of experimental accounting research that uses abstract tasks to test psychological mechanisms and then infers that the results pertaining to these psychological mechanisms generalizes to real-world accounting tasks. For other examples of this type of research see Choi, Hecht, and Tayler (2012) who use a video game for their experimental task, Christ et al. $(2016,2012)$ who use the same typing task to proxy for internal controls, and Drake, Haka, and Ravenscroft (1999) who have participants build with legos for their experimental task.

Participants began by answering demographic questions and then completed a short typing pretest with no data-entry controls to become familiar with the typing program prior to beginning the measured portion of the task. After completing the practice portion, participants learned of the data entry control condition to which they were assigned (if one was assigned) and completed multiple screens with the data-entry controls enforced. Within our typing task, we follow the methodology of Christ et al. (2012) and implement four different manipulations on internal controls, consisting of the following:

1. No control condition: No controls were implemented. This is identical to the pretest administered prior to the actual test.

2. Preventive control condition: Controls were implemented on some characters such that if participants did not enter the correct character: (1) they could not advance to the next character until they had entered the correct character and (2) the incorrectly entered character would turn red. As part of the instructions, participants were given an example and told to try entering the wrong characters to observe what happened.

3. Detective control, immediate feedback condition: Controls were implemented on some characters such that, if participants entered the wrong character, the missed character would turn red but the cursor would advance (i.e., participants could not correct the mistake, but would immediately see that they had made the mistake). As part of the instructions, participants were instructed to try entering the wrong characters on an example line of text.

4. Detective control, delayed feedback condition: Controls were implemented on some characters such that, if participants entered the wrong character, the missed character would 
turn red after the participant finished entering all of the characters on the screen. Specifically, the participant would finish entering all text on a screen, hit continue, and a second screen would show what characters (with controls) the participant had missed. Similar to the detective immediate feedback condition, participants in this condition could not correct their mistakes. As part of the instruction, participants were instructed to try entering the wrong characters on an example line of text.

By randomly assigning participants to one of these four groups, we can observe if there are significant differences in depletion between those who have internal controls placed on a task and those who have no internal controls on the task. Additionally, we will also be able to observe differences between the different classifications of internal controls in our experiment. The typing test took participants about 10 minutes to complete. Any differences in self-control depletion between these four groups is measured in the second task of the experiment. We note that this implementation of internal controls has been effective in producing performance differences in previous research (see Christ et al. 2012; Christ et al. 2016).

\section{Dependent Task}

The second task was used to capture the depletion effects of the initial depleting task. For this experiment, we administer an anagram-solving task consisting of five unsolvable anagrams. Anagrams are word tasks where the order of letters in a word are mixed up and the person has to determine what word(s) the letters can spell. As an example, participants might be given the letters "meeoaws" and be expected to come up with the word "awesome." We time how long each participant spent trying to solve the anagrams before giving up, with a maximum time of 10 minutes to complete the task. Persistence in attempting to solve unsolvable anagrams is an effective measure of depletion because depleted individuals will give up sooner than non-depleted individuals due to diminished self-control capacity (Muraven et al. 1998). Unsolvable anagram tasks are commonly used in ego depletion literature to measure depletion and have proven to be an effective method of capturing differences in depletion (e.g., Burkley 2008; Ciarocco, Sommer, and Baumeister 2001; Tyler 2008; Tyler and Burns 2009).

\section{Post-Experiment Questionnaire}

Previous research has shown that ego depletion can have downstream effects on ethical behavior (Gailliot, Gitter, Baker, and Baumeister 2012; Mead et al. 2009; Barnes et al. 2011;Gino et al. 2011). To capture these potential downstream effects, we measure ethical judgments using a series of vignettes (Barnett, Bass, and Brown 1994). Barnett et al. (1994) asks participants to measure a series of vignettes on four dimensions of ethicality. The following is an example of one of the ten vignettes used in this portion of the experiment: "In pricing a life-saving drug, a druggist charged a destitute patient ten times the cost of making the drug." Participants rank each scenario on a 1-to-9 scale on the following four dimensions: fair/unfair, just/unjust, morally right/not morally right, and ethical/unethical. Measuring across these four dimensions allows for a more complete picture of how a participant feels about each scenario (e.g. something may be unethical but still be fair). However, this distinction would not be captured by simply asking a participant whether something is unethical or not. We also administered the Ethics Position Questionnaire (or "EPQ") to measure ideology. By asking participants if they agree or disagree with different statements about their own ethical beliefs, individuals may be classified into one of four ideological categories based on their levels of idealism and relativism. Examples of statements included in the EPQ include: "The existence of potential harm to others is always wrong, irrespective of the benefits to be gained" and "No rule concerning lying can be formulated; whether a lie is permissible or not permissible totally depends upon the situation." Subjects are asked to evaluate if they agree or disagree with each statement on a 1-to-7 scale. Half of the questions in the EPQ are used to determine if a subject favors high or low idealism, while the other half determines a preference for either high or low relativism. These dimensions form a 2 x 2 grid of potential ideologies that participants may be sorted into. The EPQ has been shown to have sufficient levels of internal consistency, and its two-factor structure appears to be stable (Schlenker and Forsyth, 1977; Forsyth 1980). Differences in underlying ideology 
have been found to account for differences in ethical judgments (Forsyth and Nye 1990; Forsyth 1992), so classifying participants based on their ideology is a useful way of explaining any potential differences measured in ethical judgments from the previously described vignettes. We also wanted to examine if any one ideology would become more prevalent than would otherwise be expected after inducing a state of depletion. Such a finding would suggest that depletion may temporarily affect one's ideological outlook in terms of idealism and relativism.

Measuring both ethical judgment and ideology allows us to see if only surface-level ethical judgments are affected by depletion or if the effects of depletion run deep enough to temporarily affect ideology. These measures should provide a clear picture of how and why ethical breakdowns occur as a result of depletion.

\section{Results}

Table 1 presents the results of our first experiment. In Panel A, we present descriptive statistics of the amount of time spent on the ego depletion task (more time means less depletion). Using an ANOVA, we find no significant differences between conditions ( $\mathrm{p}$-values $>0.10$ ). We perform contrast comparisons between each pair of conditions and find no significant differences (all p-values $>0.10$ ). Thus, these results suggest that internal controls are not associated with self-control as stated in our research question.

TABLE 1

\section{EXPERIMENT 1 RESULTS}

Panel A: Effects of Internal Control Conditions on Ego Depletion

\section{Condition}

Preventive

Detective Immediate Feedback

Detective Delayed Feedback

No Control

F-stat Test for Differences

P-values (two-tailed)

Significant Contrast Comparisons Between Conditions
Ego Depletion

$241.7(146.5)$

$231.2(155.6)$

$247.6(169.9)$

$257.7(178.5)$

0.17

0.914

None

Panel B: Effects of Internal Control Conditions on Ethical Judgments and Ethical Scenarios

\section{Ethical Ideology}

\begin{tabular}{|c|c|c|c|c|c|c|}
\hline \multirow[b]{2}{*}{ Condition } & & \\
\hline & Idealism & Relativism & Fairness & Just & Morally Right & Ethical \\
\hline Preventive & $7.05(9.5)$ & $-4.28(9.3)$ & $5.3(1.3)$ & $5.4(0.9)$ & $6.1(0.8)$ & $5.9(0.9)$ \\
\hline Detective & $4.30(7.1)$ & $-3.81(7.6)$ & $5.5(1.0)$ & $5.6(1.0)$ & $5.9(0.9)$ & $5.7(1.1)$ \\
\hline Immediate & & & & & & \\
\hline Feedback & & & & & & \\
\hline Detective & $2.47(8.2)$ & $-2.87(10.6)$ & $5.2(1.1)$ & $5.2(1.0)$ & $5.5(0.8)$ & $5.4(0.9)$ \\
\hline Delayed & & & & & & \\
\hline Feedback & & & & & & \\
\hline No Control & $3.26(7.1)$ & $-3.42(6.7)$ & $5.0(1.4)$ & $5.4(1.0)$ & $6.0(0.9)$ & $5.7(1.0)$ \\
\hline $\begin{array}{l}\text { F-stat Test } \\
\text { for }\end{array}$ & 2.40 & 0.18 & 1.48 & 0.95 & 3.93 & 1.47 \\
\hline Differences & & & & & & \\
\hline $\begin{array}{l}\text { P-values } \\
\text { (two-tailed) }\end{array}$ & 0.070 & 0.908 & 0.222 & 0.419 & 0.01 & 0.225 \\
\hline
\end{tabular}

Ethical Judgments 


\begin{tabular}{|c|c|c|c|c|c|c|}
\hline $\begin{array}{l}\text { Significant } \\
\text { Contrast } \\
\text { Compariso } \\
\text { ns Between } \\
\text { Conditions }\end{array}$ & $\begin{array}{l}\mathrm{DD}<\mathrm{P},(\mathrm{p}- \\
\text { value }=.014), \\
\mathrm{P}>\mathrm{NC},(\mathrm{p}- \\
\text { value }= \\
0.040)\end{array}$ & None & $\begin{array}{l}\mathrm{DI}>\mathrm{NC} \\
(\mathrm{p} \text {-value }= \\
0.040)\end{array}$ & None & $\begin{array}{l}\mathrm{DD}<\mathrm{P},(\mathrm{p}- \\
\text { value }=0.002) \\
\mathrm{DI},(\mathrm{p} \text {-value } \\
=0.070) ; \mathrm{NC},(\mathrm{p}- \\
\text { value }=0.007)\end{array}$ & $\begin{array}{l}\mathrm{DD}<\mathrm{P}(\mathrm{p}- \\
\text { value }= \\
0.040)\end{array}$ \\
\hline
\end{tabular}

Mean and (standard deviation) are presented. Results are presented for 153 participants (ranging from 37 to 40 per cell). The four conditions relate to internal control conditions. In Panel A, ego depletion measures the time participants spent (in seconds) working to solve an impossible anagram task. Greater time spent suggests greater self-control and thus lower ego depletion. In Panel B, Idealism and Relativism come from the 20 questions in the EPQ from Forsyth and Nye (1990) and Forsyth (1992) used to measure ideology. All scores are measured on a seven-point strongly disagree (-3) to strongly agree (3) scale, with higher scores indicating higher levels of idealism or relativism and lower scores representing lower levels of idealism and relativism. For ethical judgments, Fairness, Just, Right, and Ethical are the average of scores for five different ethical dilemmas that ask participants whether the situation is fair, just, right, and ethical on 9 point scales. Lower scores indicate that the morally-questionable situation is seen as fair, just, morally right, or ethical, while higher scores indicate that the morally-questionable situation is seen as unfair, unjust, morally wrong, or unethical. The f-tests in Panel A and Panel B are the test statistics of comparing all four conditions for differences using an ANOVA. The contrast tests are post-hoc comparisons of conditions; only comparisons that have a p-value $<0.10$ are reported.

Panel B of Table 1 presents descriptive statistics and statistical tests of the ethical component of our first experiment. Our two measures of ethical ideology, "Idealism" and "Relativism," do not show any significant differences among control conditions, with the exception of Idealism for the preventive control condition. Subjects in the preventive control condition were measured as being more idealistic than those in the other three control conditions (p-value=.070). Consistent with Barnett et al. (1994), we find that this difference in ideology corresponded with less-lenient assessments of the different ethical scenarios, as subjects in the preventive control condition rated the five scenarios as less morally right and less ethical than any other group.

For the four different dependent variables measuring ethical judgments, only one dependent variable, "Morally Right," shows statistically significant differences between conditions (p-value $<0.01$ ). We observe a few significant contrast comparisons, even though only one of the ANOVA comparisons shows significant differences. In the "Fairness" measure of ethicality, subjects in the no control condition rated the scenarios as less fair than those in the detective-immediate condition ( $p$-value $=0.040$ ). In the "Morally Right" measure of ethicality, participants in the detective-delayed condition rated the scenarios as less morally right than those in all three other control conditions ( $\mathrm{p}$-value $=0.002$ for preventive, 0.070 for detective-immediate, and 0.007 for no control). Participants in the detective-delayed condition also rated the various scenarios as less ethical than those in the preventive condition ( $\mathrm{p}$-value $=0.040$ ).

We also correlate the scores of ego depletion with our ethics measures. We observe that our measure of ego depletion is marginally significantly negatively correlated with "Fairness" $(\mathrm{r}=-0.144$, $\mathrm{p}$-value $=$ 0.074 ) but is not significantly correlated with any other measures of ethicality (all p-values $>0.10$ ).

Given these results, the most favorable interpretation of these results suggests some possible relation between different types of internal control and ethical decision-making, but not because of differences in self-control. Given the relatively weak results, we chose to run the experiment a second time, making several changes to see if we can find effects that are more robust. We discuss the second experiment and results below.

\section{EXPERIMENT 2}

\section{Procedure}

In the second experiment, we altered design elements of both the depleting task and the dependent task in order to try and create greater power for observing results. For the depleting task, we continued to use the same typing task and control manipulations used in Experiment 1, but we took several steps to 
enhance the self-control demands of the task. First, we changed the text that participants typed in the typing program from complete sentences to arbitrary product codes. This was done to make the task require more effort and care, as tasks that require subjects to control attention, maintain vigilance, and control their focus have been shown to induce depletion in prior studies (Baumeister et al. 1998; Schmeichel 2007). Next, we added a financial incentive to the typing task as a means of increasing selfcontrol exertion during the depleting task. This is in accordance with Muraven, Rosman, and Gagne (2007), which found that subjects who were rewarded based on performance on a depleting task performed worse on subsequent self-control tasks than those whose reward did not depend on performance. This link between incentives and depletion could potentially be explained by the fact that incentives are generally believed to increase effort (Bonner and Sprinkle 2002). Therefore, we expected the incentive to lead to increased use of self-control as participants exert themselves more to increase performance. As a way of measuring whether participants believe experiment 2 was harder (and thus required more self-control) than in experiment 1, we asked participants to rate how much they agreed or disagreed with the statements "I found the typing test to be difficult" and "I had to focus while completing the typing test" on a one-to-seven scale. In the first experiment, the average of the two questions was a 4.8 on a seven-point scale and in the second experiment it was a 5.5, which is significantly greater than in the first experiment ( $\mathrm{p}$-value $<0.01$ ). While self-reported task difficulty is not necessarily a proxy for depletion, it suggests that we were at least successful in increasing the difficulty of the task. The structure of the incentive was such that all participants were entered into a drawing for a cash prize of \$20; however, the faster participants typed, the greater likelihood they had of winning the random drawing. We told participants of the compensation scheme before they performed the typing task. Finally, we also increased the frequency of the controls from 75 percent of all characters to 90 percent of all characters. This choice was made in an attempt to increase the overall contrast between conditions.

The remaining design changes were made to the second task of the experiment. We once again used the same unsolvable anagram task that we used in Experiment 1, but we altered the wording in the instructions so that participants were more aware of the fact that they could end the task at will or skip a word if they were unable to solve it. We also reduced the number of anagrams used in the task from five to two, and only one of the two anagrams was unsolvable. This was done so that differences in persistence between those who choose to give up quickly and those who choose to persist would be easier to observe. After completing the anagram task, we used the same questionnaires used in Experiment 1 to measure ethical judgments and ideology.

\section{Results}

Table 2 presents the results of our second experiment. This table follows the same pattern of presenting results as Table 1. In Panel A, we find no significant differences between conditions when considered jointly or in individual contrast comparisons (all p-values $>0.10$ ). Thus, we again fail to find evidence that internal controls influence self-control. In Panel B, we find no significant differences between the internal control conditions and measures of ethical judgments or ideology (all p-values $>$ 0.10 ). We note that the results for the two significant measures in experiment 1 ("Morally Right" and "Ethical"), although not statistically significant in experiment 2, were in the opposite direction of the results in experiment 1 . We also correlate anagram task persistence with our ethics measures. We observe no significant correlations with the ethics measures (all p-values $>0.10$ ).

Even with our efforts to increase depletion through adding an incentive to the depleting task, increasing the control frequency, and changing the text participants were required to type, we were unable to observe significant differences in ego depletion among the different control types. Furthermore, we were not able to replicate the few significant findings from the first experiment, instead observing a different directional pattern of results. We also note that both experiments had over 150 participants, suggesting that we should have sufficient power to detect a meaningful relationship between our variables. 
TABLE 2

EXPERIMENT 2 RESULTS

Panel A: Effects of Internal Control Conditions on Ego Depletion Condition

Ego Depletion

Preventive

59.3 (47.7)

Detective Immediate Feedback

$50.5(56.9)$

Detective Delayed Feedback

$72.4(70.2)$

No Control

$66.6(67.4)$

F-stat Test for Differences

0.89

P-values (two-tailed)

0.447

Significant Contrast Comparisons Between Conditions

None

Panel B: Effects of Internal Control Conditions on Ethical Judgments and Ethical Scenarios

\begin{tabular}{|c|c|c|c|c|c|c|}
\hline \multirow[b]{2}{*}{ Condition } & \multicolumn{2}{|c|}{ Ethical Ideology } & \multicolumn{4}{|c|}{ Ethical Judgments } \\
\hline & Idealism & Relativism & Fairness & Just & Morally Right & Ethical \\
\hline Preventive & $\begin{array}{l}6.33 \\
(6.8)\end{array}$ & $-3.33(10.0)$ & $5.4(1.2)$ & $5.4(1.1)$ & $5.8(0.8)$ & $5.8(0.8)$ \\
\hline Detective Immediate Feedback & $\begin{array}{l}4.89 \\
(8.8)\end{array}$ & $-4.19(8.9)$ & $5.4(0.7)$ & $5.5(0.7)$ & $5.8(0.6)$ & $5.7(0.7)$ \\
\hline Detective Delayed Feedback & $\begin{array}{l}4.03 \\
(9.9)\end{array}$ & $-4.43(8.0)$ & $5.4(1.0)$ & $5.4(1.0)$ & $5.8(1.0)$ & $5.7(1.0)$ \\
\hline No Control & $\begin{array}{l}5.13 \\
(8.7) \\
\end{array}$ & $-5.45(7.4)$ & $5.3(1.0)$ & $5.4(0.9)$ & $5.6(0.9)$ & $5.6(0.8)$ \\
\hline F-stat Test for Differences & 0.45 & 0.39 & 0.04 & 0.22 & 0.41 & 0.65 \\
\hline $\begin{array}{l}\text { P-values (two-tailed) } \\
\text { Significant Contrast } \\
\text { Comparisons Between } \\
\text { Conditions }\end{array}$ & $\begin{array}{l}0.721 \\
\text { None }\end{array}$ & $\begin{array}{l}0.761 \\
\text { None }\end{array}$ & $\begin{array}{l}0.990 \\
\text { None }\end{array}$ & $\begin{array}{c}0.880 \\
\text { None }\end{array}$ & $\begin{array}{l}0.748 \\
\text { None }\end{array}$ & $\begin{array}{l}0.584 \\
\text { None }\end{array}$ \\
\hline
\end{tabular}

Mean and (standard deviation) are presented. Results are presented for 152 participants (ranging from 36 to 40 per cell). See Table 1 for discussion of interpreting this table. The difference in experiment 2 is that only 2 anagrams were presented instead of 5 anagrams.

\section{EXPERIMENT 3}

\section{Procedure}

Experiment 3 is a third attempt to observe differences in depletion between subjects by manipulating internal controls. For this experiment, we maintain the same two-task paradigm used in Experiments 1 and 2 and use the same first task as Experiment 2, but alter the second task from an unsolvable anagram task to a cognitive task known as the Stroop task. The Stroop task is one of the mostly commonly used self-control tasks in the depletion literature (Fennis, Janssen, and Vohs 2009; Gailliot et al. 2007; Gailliot Schmeichel, and Baumeister 2006; Inzlicht and Gutsell 2007; Richeson and Shelton 2003; Richeson and Trawalter 2005; Shamosh and Gray 2007; Trawalter and Richeson 2006; Webb and Sheeran 2003).The Stroop task displays a series of color words (such as "red" or "blue") in a color of text that may or may not match the word itself. Participants must then type the letter that corresponds with the first letter of the color of the text, not what the word says. For example, if the written word "Yellow" is on the screen, but it is displayed in a blue font, the participants should enter " $b$ " to correspond to the blue color of the font. Because subjects must override the impulse to type the first letter of the written text, self-control is 
required to be able to distinguish between the color of the text and the word itself. Our dependent variables of interest in this task are the response time in incongruent trials (depleted individuals should take longer to respond) and accuracy (depleted individuals should answer more questions incorrectly).

The rest of Experiment 3 was the same as Experiment 2, but we removed the ethical questionnaires and scenarios, opting to forgo further testing on downstream ethical consequences of depletion until we could successfully establish a link between internal controls and depletion.

\section{Results}

Table 3 contains the results for the Stroop task conducted in Experiment 3. Similar to Experiment 2, we find no significant differences for either measure of ego depletion ( $p$-values $>0.10$ ). We also find no significant differences between conditions when we examine contrast tests between each pair of conditions (all p-values $>0.10$ ). We obtain these results even though we tested 157 participants-which should be sufficient to observe meaningful differences between conditions.

Considering all three experiments together, we conclude that different types of internal controls do not cause different amounts of ego depletion or result in differences in ethical decision making. We have more confidence in these null results than in some studies because we used multiple experiments that altered how we measured ego depletion, altered the internal control task to create the best situations possible to observe depletion, used an internal control task that had produced significant and theoryconsistent results in past studies, had a relatively large sample size to observe a reasonable sized effect, and observed different positive/negative patterns of what types of internal controls caused more/less depletion (even though differences were rarely significant). Thus, we conclude that internal controls, regardless of whether they are preventive or detective, do not appear to have an effect on ego depletion or ethical judgments and ideology.

TABLE 3

\section{EXPERIMENT 3 RESULTS}

\begin{tabular}{|c|c|c|}
\hline Condition & Ego Depletion - Accuracy & Ego Depletion - Time Difference \\
\hline Preventive & $0.95(0.05)$ & $104.8(77.3)$ \\
\hline Detective Immediate Feedback & $0.96(0.04)$ & $118.8(76.9)$ \\
\hline Detective Delayed Feedback & $0.95(0.05)$ & $132.2(78.9)$ \\
\hline No Control & $0.94(0.09)$ & $104.8(77.3)$ \\
\hline F-stat Test for Differences & 0.59 & 0.96 \\
\hline P-values (two-tailed) & 0.622 & 0.415 \\
\hline $\begin{array}{l}\text { Significant } \\
\text { Comparisons } \\
\text { Conditions }\end{array}$ & None & None \\
\hline
\end{tabular}

Mean and (stand deviation) are presented. Results are presented for 157 participants (ranging from 39 to 40 per cell). The four conditions relate to internal control conditions. There are two measures of ego depletion both measured using a Stroop task. Ego Depletion - Accuracy is the percentage of correctly answered question in the Stroop task. Higher values suggest lower ego depletion. Ego Depletion - Time Differences is the number of seconds difference between responses for congruent and incongruent trials. Higher values suggest more ego depletion. The f-tests in are the test statistics of comparing all four conditions for differences using an ANOVA. The contrast tests are post-hoc comparisons of conditions; only comparisons that have a p-value $<0.10$ are reported. 


\section{CONCLUSION}

The purpose of our study is to investigate the relationship between internal controls and self-control depletion. While different control classifications possess different attributes that could plausibly affect the self-control demands of a given task, we found no statistically significant relationship between controls and depletion or ethical judgments and ideology. We believe these null results are credible because of the multiple different steps we took to find results, including using different measures of depletion, replicating across multiple experiments, and using internal controls that had been effective in prior research.

We interpret our results to mean that the type of control placed on a task poses no threat of increasing the risk of unethical behavior due to decreased self-control. This finding should be useful for managers, audit committees, and auditors because these parties rely upon internal controls. Those who design accounting information systems should also find these results useful as they suggest there is not a tradeoff between types of control and ethical decision-making.

Our results add to the continuing dialogue surrounding ego depletion theory and demonstrate that our understanding of self-control may not be as complete as we once thought it was (Haggar et al. 2016; Lurquin et al. 2016; Luquin and Miyake 2017, Job et al. 2010; Schmeichel and Vohs 2009; Ryan and Deci 2008). To further our understanding of the subject, researchers may choose to find different ways of examining self-control failure beyond the conventionally used two-task paradigm and create new frameworks through which we can understand self-control failure.

Finally, we encourage researchers to continue to study the unintended consequences of internal controls across various dimensions, including self-control. Our study attempted to measure self-control depletion using the two-task paradigm that is commonly used in the depletion literature, but there are indeed other methods to measure self-control failure, including long-term employee performance and archival data reporting on instances of fraud and accounting irregularities. Studying the relationship between different kinds of internal controls and these measures of self-control failure could provide another valuable angle on the relationship between controls and self-control that would help us understand both topics more precisely. Such an understanding will help businesses to account for the unintended consequences that may occur as a result of the way that their systems are designed.

\section{REFERENCES}

Ashbaugh-Skaife, H., Collins, D.W., \& Lafond, R. (2009). The effect of SOX internal control deficiencies on firm risk and cost of equity. Journal of Accounting Research, 47(1), 1-43.

Barnes, C.M., Schaubroeck, J., Huth, M., \& Ghumman, S. (2011). Lack of sleep and unethical conduct. Organizational Behavior and Human Decision Processes, 115(2), 169-180.

Barnett, T., Bass, K., \& Brown, G. (1994). Ethical ideology and ethical judgment regarding ethical issues in business. Journal of Business Ethics, 13(6), 469-480.

Baumeister, R.F., Bratslavsky, E., Muraven, M., \& Tice, D.M. (1998). Ego depletion: Is the active self a limited resource? Journal of Personality and Social Psychology, 74(5), 1252-1265.

Baxter, R., Holderness, D.K., \& Wood, D.A. (2016a). Applying basic gamification techniques to IT compliance training: Evidence from the lab and field. Journal of Information Systems, Forthcoming. DOI: 10.2308/isys-51341.

Baxter, R., Holderness, D.K., \& Wood, D.A. (2016b). The effects of gamification on corporate compliance training: A field experiment of True Office anti-corruption training programs. Retrieved from SSRN: http://papers.ssrn.com/sol3/papers.cfm?abstract_id=2766683

Beneish, M.D., Billings, M.B., \& Hodder, L.D. (2008). Internal control weaknesses and information uncertainty. The Accounting Review, 83(3), 665-703. 
Bonner, S.E., \& Sprinkle, G.B. (2002). The effects of monetary incentives on effort and task performance: Theories, evidence, and a framework for research. Accounting, Organizations and Society, 27(4), 303-345.

Burkley, E. (2008). The role of self-control in resistance to persuasion. Personality and Social Psychology Bulletin, 34(3), 419-431.

Choi, J., Hecht, G.W., \& Tayler W.B. (2012). Lost in translation: The effects of incentive compensation on strategy surrogation. The Accounting Review, 87(4), 1135-1163.

Christ, M.H., Emett, S.A., \& Summers, S.L., \& Wood D.A. (2012). The effects of preventive and detective controls on employee performance and motivation. Contemporary Accounting Research, 29(2), 432-452.

Christ, M.H., Masli, A., Sharp, N.Y., \& Wood, D.A. (2015). Rotational internal audit programs and financial reporting quality: Do compensating controls help? Accounting, Organizations and Society, 44, 37-59.

Christ, M.H., Sedatole K.L., Towry, K.L., \& Thomas, M.A. (2008). When formal controls undermine trust and cooperation. Strategic Finance, 89(7), 39-44.

Christ, M.H., Emett, S., Tayler, W.B., \& Wood, D.A. (2016). Compensation or feedback: Motivating performance in multidimensional tasks. Accounting, Organizations and Society, 50, 27-40.

Ciarocco, N.J., Sommer, K.L., \& Baumeister, R.F. (2001). Ostracism and ego depletion: The strains of silence. Personality and Social Psychology Bulletin, 27, 1156-1163.

Committee of Sponsoring Organizations of the Treadway Commission (COSO). (1992). Enterprise risk management: Integrated framework. New York: AICPA.

Committee of Sponsoring Organizations of the Treadway Commission (COSO). (2004). Enterprise risk management: Integrated framework. New York: AICPA.

Committee of Sponsoring Organizations of the Treadway Commission (COSO). (2013). Internal Control - Integrated Framework. New York: AICPA.

Doyle, J.T., Weili, G., \& McVay, S. (2007). Accruals quality and internal control over financial reporting. The Accounting Review, 82(5), 1141-1170.

Drake, A.R., Haka, S.F., \& Ravenscroft, S.P. (1994). Cost system and incentive structure effects on innovation, efficiency and profitability in teams. The Accounting Review, 74(3), 323-345.

Ettredge, M.L., Chan, L., \& Sun, L. (2006). The impact of SOX Section 404 internal control quality assessment on audit delay in the SOX era. Auditing: A Journal of Practice \& Theory, 25(2), 1-23.

Feng, M., Li, C., \& McVay, S. (2009). Internal control and management guidance. Journal of Accounting and Economics, 48(2), 190-209.

Fennis, B.M., Janssen, L., \& Vohs, K.D. (2009). Acts of benevolence: A limited-resource account of compliance with charitable requests. Journal of Consumer Research, 35(6), 906-924.

Forsyth, D.R. (n.d.). A taxonomy of ethical ideologies. (1980). Journal of Personality and Social Psychology, 39(1), 175-184.

Forsyth, D.R. (1992). Judging the morality of business practices: The influence of personal moral philosophies. Journal of Business Ethics, 11, 461-470.

Forsyth, D.R., \& Nye J.L. (1990). Personal moral philosophies and moral choice. Journal of Research in Personality, 24, 398-414.

Frey, B.S. (1993). Does monitoring increase work effort? The rivalry with trust and loyalty. Economic Inquiry, 31(4), 663-670.

Gailliot, M.T., \& Baumeister, R.F. (2007). The physiology of willpower: Linking blood glucose to selfcontrol. Personality and Social Psychology Review, 11(4), 303-327.

Gailliot, M.T., Baumeister, R.F., DeWall, C.N., Maner, J.K., Plant, E.A., Tice, D.M., Brewer, L.E., \& Schmeichel, B.J. (2007). Self-control relies on glucose as a limited energy source: willpower is more than a metaphor. Journal of Personality and Social Psychology, 92(2), 325-336.

Gailliot, M.T., Gitter, S.A., Baker, M.D., \& Baumeister, R.F. (2012). Breaking the rules: Low trait or state self-control increases social norm violations. Psychology, 3(12), 1074. 
Gailliot, M.T., Schmeichel, B.J., \& Baumeister, R.F. (2006). Self- regulatory processes defend against the threat of death: Effects of self-control depletion and trait self-control on thoughts and fears of dying. Journal of Personality and Social Psychology, 91, 49-62.

Geringer, J.M., \& Hebert, L. (1989). Control and performance of international joint ventures. Journal of International Business Studies, 20(2), 235-254.

Gino, F., Schweitzer, M.E., Mead, N.L., \& Ariely, D. (2011). Unable to resist temptation: How selfcontrol depletion promotes unethical behavior. Organizational Behavior and Human Decision Processes, 115(2), 191-203.

Hagger, M.S., Wood, C., Stiff, C., \& Chatzisarantis, N.L. (2010). Ego depletion and the strength model of self-control: a meta-analysis. Psychological Bulletin, 136(4), 495-525.

Hagger, M.S., et al. (2016). A Multilab preregistered replication of the ego-depletion effect. Perspectives on Psychological Science, 11, 546-573.

Hogan, C.E., \& Wilkins, M.S. (2008). Evidence on the audit risk model: Do auditors increase audit fees in the presence of internal control deficiencies? Contemporary Accounting Research, 25(1) 219242.

Hoitash, R., Hoitash, U., \& Bedard, J.C. (2008). Internal control quality and audit pricing under the Sarbanes-Oxley Act. Auditing: A Journal of Practice \& Theory, 27(1), 105-126.

Hurley, P.J. (2015). Ego depletion: applications and implications for auditing research. Journal of Accounting Literature, 35, 47-76.

Inzlicht, M., \& Gutsell, J.N. (2007). Running on empty neural signals for self-control failure. Psychological Science, 18(11), 933-937.

Job, V., Dweck, C., \& Walton, G. (2010). Ego depletion: Is it all in your head? Implicit theories about willpower affect self-regulation. Psychological Science, 21, 1686-1693.

Kremin J. (2014). Control Yourself! The Impact of Self-Control on Auditors' Ability to Practice Professional Skepticism. Retrieved from SSRN: http://papers.ssrn.com/sol3/papers.cfm?abstract_id=2382823.

Lurquin, J.H., Michaelson, L.E., Barker, J.E., Gustavson, D.E., von Bastain, C.C., Carruth, N.P., \& Miyake A. (2016). No evidence of the ego-depletion effect across task characteristics and individual differences: A pre-registered study. PLOS ONE, 11(2). https://doi.org/10.1371/journal.pone.0147770

Lurquin, J.H., \& Miyake, A. (2017). Challenges to ego-depletion research go beyond the replication crisis: A need for tackling the conceptual crisis. Frontiers in Psychology, 8. http://doi.10.3389/fpsyg.2017.00568.

Majors, T.M., Shefchik, L.B., \& Vitalis, A. (2014). The Interactive Effect of Ego Depletion and Trait Skepticism on Auditor Performance. Retrieved from SSRN: http://ssrn.com/abstract=2408227

Mead, N.L., Baumeister, R.F., Gino, F., Schweitzer, M.E., \& Ariely, D. (2009). Too tired to tell the truth: Self-control resource depletion and dishonesty. Journal of Experimental Social Psychology, 45(3), 594-597.

Medcof, J.W. (1997). Why too many alliances end in divorce. Long Range Planning, 30(5), 718-732.

Moller, A.C., Deci, E.L., \& Ryan, R.M. (2006). Choice and ego-depletion: The moderating role of autonomy. Personality and Social Psychology Bulletin, 32(8), 1024-1036.

Muraven, M., Gagné, M., \& Rosman, H. (2008). Helpful self-control: Autonomy support, vitality, and depletion. Journal of Experimental Social Psychology, 44(3), 573-585.

Muraven, M.M., Rosman, H., \& Gagné, M. (2007). Lack of autonomy and self-control: Performance contingent rewards lead to greater depletion. Motivation and Emotion, 31(4), 322-330.

Muraven, M., Shmueli, D., \& Burkley, E. (2006). Conserving self-control strength. Journal of Personality and Social Psychology, 91(3), 524.

Muraven, M., Tice, D.M., \& Baumeister, R.F. (1998). Self-control as a limited resource: Regulatory depletion patterns. Journal of Personality and Social Psychology, 74(3), 774-789.

Ogneva, M., Subramanyam, K.R., \& Raghunandan, K. (2007). Internal control weakness and cost of equity: Evidence from SOX Section 404 disclosures. The Accounting Review, 82(5), 1255-1297. 
Richeson, J.A., \& Shelton, J.N. (2003). When prejudice does not pay: Effects of interracial contact on executive function. Psychological Science, 14(3), 287-290.

Richeson, J.A., \& Trawalter, S. (2005). Why do interracial interactions impair executive function? A resource depletion account. Journal of Personality and Social Psychology, 88(6), 934-947.

Romney, M.B., \& Steinbart, P. (2015). Accounting Information Systems, $13^{\text {th }}$ ed. Upper Saddle River, NJ: Prentice Hall.

Ryan, R.M., \& Deci, E.L. (2008). From ego depletion to vitality: Theory and findings concerning the facilitation of energy available to the self. Social and Personality Psychology Compass, 2/2, 702 717.

Schlenker, B.R., \& Forsyth, D.R. (1977). On the ethics of psychological research. Journal of Experimental Social Psychology, 13(4), 369-396.

Schmeichel, B.J. (2007). Attention control, memory updating, and emotion regulation temporarily reduce the capacity for executive control. Journal of Experimental Psychology, 136(2), 241.

Schmeichel, B.J., \& Vohs, K.D. (2009). Self-affirmation and self-control: Affirming core values counteracts ego depletion. Journal of Personality and Social Psychology, 96, 770-782.

Shamosh, N.A., \& Gray, J.R. (2007). The relation between fluid intelligence and self-regulatory depletion. Cognition \& Emotion, 21(8), 1833-1843.

Tenbrunsel, A.E., \& Messick, D.M. (1999). Sanctioning systems, decision frames, and cooperation. Administrative Science Quarterly, 44(4), 684-707.

Trawalter, S., \& Richeson, J.A. (2006). Regulatory focus and executive function after interracial interactions. Journal of Experimental Social Psychology, 42(3), 406-412.

Tice, D.M., Baumeister, R.F., Shmueli, D., \& Muraven, M. (2007). Restoring the self: Positive affect helps improve self-regulation following ego depletion. Journal of Experimental Social Psychology, 43(3), 379-384.

Tyler, J.M. (2008). In the eyes of others: Monitoring for relational value cues. Human Communication Research, 34(4), 521-534.

Tyler, J.M., \& Burns, K.C. (2008). After depletion: The replenishment of the self's regulatory resources. Self and Identity, 7(3), 305-321.

Tyler, J.M., \& Burns K.C. (2009). Triggering conservation of the self's regulatory resources. Basic and Applied Social Psychology, 31(3), 255-266.

Vohs, K.D., \& Schmeichel, B.J. (2003). Self-regulation and extended now: Controlling the self alters the subjective experience of time. Journal of Personality and Social Psychology, 85(2), 217-230.

Wallace, H.M., \& Baumeister, R.F. (2002). The effects of success versus failure feedback on further selfcontrol. Self and Identity, 1(1), 35-41.

Webb, T.L., \& Sheeran, P. (2003). Can implementation intentions help to overcome ego-depletion? Journal of Experimental Social Psychology, 39(3), 279-286. 